\title{
Comparison of magnetic parameters of urban atmospheric particulate matter with pollution and meteorological data.
}

\author{
Adrian R. Muxworthy, Jürgen Matzka and Nikolai Petersen \\ Institut für Geophysik, Universität München, Theresienstr. 41, 80333 Munich, \\ Germany. E-mail: adrian@geophysik.uni-muenchen.de
}

\begin{abstract}
Magnetic hysteresis parameters were measured for three sample sets of respirable atmospheric particulate matter collected in Munich, Germany, and were compared with pollution data and meteorological data using principal component analysis. The samples sets were collected at two urban locations by the filter method during August 1998 to July 1999. The samples were measured in weekly batches, with the longest data set being 40 weeks. It was found that the magnetic hysteresis parameters generally had a stronger correlation with the meteorological data than with the pollution data. Correlations with the pollution data were found to be highly site dependent, that is, at one location there was a strong relationship between the magnetic parameters and vehicular derived combustion pollutants, but not at the other. The primary magnetic mineral was identified to be magnetite, in the grain size range $0.2-5 \mu \mathrm{m}$, which is small enough to be particularly dangerous humans as the particles can be inhaled deeply into the lung. The grain-size dependent magnetic hysteresis parameters were strongly dependent on relative humidity. The concentration of magnetic particulate matter was in the range $0.3-0.6 \%$ by mass. As the amount of magnetic particulate matter did not always correlate significantly with the total particulate mass, then this implies that the use of magnetic susceptibility as a rapid method of assessing the bulk magnetic content of atmospheric particulate matter may be misleading.
\end{abstract}

Preprint submitted to Elsevier Preprint $\quad 9$ April 2001 
Key words: Magnetic measurements, iron oxide, vehicle pollution

\section{Introduction}

In recent years there has been a renewed interest in the use of magnetic techniques to investigate atmospheric particulate matter, in particular to identify and study the behaviour of anthropogenically derived particulate matter (PM) (e.g., Matzka \& Maher, 1999; Kapička et al., 2000). Magnetic minerals are common amongst pollution $\mathrm{PM}$, with typical bulk iron content found to constitute $\approx 5-15 \%$ of urban atmospheric PM, with iron oxides and hydroxides typically contributing 10-70\% of the bulk iron content (e.g., Dedik et al., 1992; Weber et al., 2000). Iron impurities in fossil fuels convert on combustion to magnetic iron oxides, i.e., magnetite, hematite or a mixture, depending on the combustion conditions. Because of its combustion origin, magnetic PM is not only dangerous in itself, but is also associated with other hazardous pollutants which are injected into the atmosphere during combustion. In addition to direct combustion derived particles, in urban environments vehicles produce other magnetic PM via abrasion/corrosion (Olson \& Skogerboe, 1975).

Previous studies have concentrated on the physical and chemical properties of the magnetic atmospheric PM fallout (e.g., Kapička et al., 2000) and/or the correlation of this magnetic fraction with either heavy metals content especially lead (e.g., Charlesworth \& Lees, 1997) or organic content (e.g., Xie et al., 2000). There is one exception to this, that is, the study of Morris et al. (1995), who examined the correlation using principal component analysis (PCA) between magnetic susceptibility of respirable pollutant particles $\left(<10 \mu \mathrm{m}\left(\mathrm{PM}_{10}\right)\right)$ collected using filters, with their mutagenic potency and organic content, and the meteorological data. They found a strong correlation between susceptibility and $\mathrm{NO}_{2}$ and $\mathrm{SO}_{2}$, and a negative correlation with wind velocity and ozone $\left(\mathrm{O}_{3}\right)$ levels.

Magnetic susceptibility measurements yield only limited information about the magnetic content if no other magnetic information is known. In this paper we extend the work of Morris et al. (1995), by examining magnetic hysteresis data for three sets of PM samples collected by the filter method with meteorological data using PCA. Magnetic hysteresis data is far more descriptive than susceptibility data as 
it yields more information about the mineralogy, grain size $(d)$ and concentration

(Dunlop \& Özdemir, 1997), which in turn provides more information about the source and characteristics of the atmospheric particulate matter. It has, however, a rather longer measuring time.

Three data sets were collected at two locations in Munich, Germany. One data set was collected using a $\mathrm{PM}_{10}$ filter and the other two with a $\mathrm{PM}_{70}(<70 \mu \mathrm{m})$ filter. The longest data series being 40 weeks, collected from $22 / 8 / 98$ to $27 / 5 / 99$. In a previous study (Matzka, 1997), hysteresis data for a similar set of samples collected in April, 1996, was measured. However, that study was restricted to a much shorter time series (12 days), and no PCA was applied.

This paper, is the first study in which magnetic hysteresis data of long time series of atmospheric particulate matter have been measured and correlated using PCA with the meteorological and pollution data. A few of the samples were examined using scanning electron microscopy (SEM) and thermomagnetic analysis, to help characterise the mineralogy and grain size of the magnetic particulate matter in the samples.

\section{Samples and methodology}

In this study, samples previously collected by the Bayerisches Landesamt für Umweltschutz (Bavarian State Department for the Environment) using the filter method were examined. Air PM was collected using Eberline FH 62 I-N dust samplers over 24-hour periods ( $24 \mathrm{~m}^{3}$ of air sampled) from two permanent stations located in areas of high traffic congestion both situated on the west side of central Munich; Pasing (EU code DEBY040) and Westendstrasse (EU code DEBY045). At Pasing, both $\mathrm{PM}_{10}(27 / 1 / 99-17 / 6 / 99)$ and $\mathrm{PM}_{70}(22 / 10 / 98-17 / 6 / 99)$ were collected, whilst only $\mathrm{PM}_{70}$ was collected at Westend (22/8/98-27/5/99). Pasing is situated $4 \mathrm{~km}$ west of Westendstrasse, and the station is classified as being in the city suburbs, whilst the Westendstrasse station is classified as being in the city centre, where the prevailing wind direction for Munich is westerly. The daily average number of cars for the period 1990-1995 was 42,000 cars per day at Pasing and 20,000 at Westend (Bayerisches Landesamt für Umweltschultz, 1998). The sampling station at Pasing 
is situated five metres from the road, whilst Westend is located six metres from Westendstrasse. Both samplers are placed four metres above the ground. Pasing is also situated less than $200 \mathrm{~m}$ from a railway yard (both diesel and electric trains, though the electric trains predominate), which is expected to contribute magnetic $\mathrm{PM}$ which is not associated with gaseous pollution data. At each site, atmospheric PM concentration, $\mathrm{CO}, \mathrm{NO}, \mathrm{NO}_{2}$ and $\mathrm{SO}_{2}$ were sampled. At a third location (Lothstrasse, EU code DEBY039) other pollution and meteorological data was measured; ozone, benzene, touline, o-dimethylbenzene, air pressure and relative humidity, wind speed, and temperature, as well as $\mathrm{CO}, \mathrm{NO}, \mathrm{NO}_{2}$ and $\mathrm{SO}_{2}$. The sampling techniques and instrumentation for this data is fully described in Bayerisches Landesamt für Umweltschultz (1998). The PM mass of each sample on the filter was determined by $\beta$-Absorption. Other meteorological data (rain and sun hours) measured at the university climate station on Theresienstrasse, was provided by Dr. P. James of the Technische Universität München. This climate station is approximately one kilometre east of Lothstrasse. All four locations are less than $6 \mathrm{~km}$ from each other. The effect of wind direction data was also considered, however, it was readily seen that due to channelling of wind in the direction of the local streets, the wind direction reflected only the local geography. It should be noted, that due to this channelling effect the wind speed data should also be treated with caution.

The magnetic hysteresis curves were measured using a variable field translation balance, with a maximum magnetic field during hysteresis of $230 \mathrm{mT}$. For further details on magnetic hysteresis see Dunlop \& Özdemir (1997) or Thompson \& Oldfield (1986).

For the purpose of this paper, we reduced the information content of each hysteresis curve to three representative parameters. Firstly the saturation moment $\left(m_{s}\right)$ which is proportional to the total magnetic content of the sample. Secondly the saturation magnetisation $\left(M_{s}\right)$, i.e., $m_{s}$ divided by the mass of the sample, which reflects the magnetic concentration within the atmospheric PM. And thirdly the coercive force $\left(H_{c}\right)$, which is dependent on the magnetic mineralogy and/or magnetic domain state of the particulate matter, and is independent of total moment or magnetic concentration of the samples. If the magnetic signal is dominated by one mineral, then $H_{c}$ is controlled only by the domain state which is directly related to grain size (Dunlop \& Özdemir, 1997). Thermomagnetic curves were measured between 
room temperature and $700{ }^{\circ} \mathrm{C}$ using a field of $100 \mathrm{mT}$ for a few samples. A selection of samples were also examined using a Zeiss DSM 960 SEM with EDX facilities. The EDX facility allows for elemental identification (including oxygen) on small particles $(\approx 1 \mu \mathrm{m})$. Due to the relative magnetic weakness of the filter samples, the filter papers were measured in weekly batches. The weekly averages for the pollution and meteorological data were determined. As a side product of this averaging, any differences between the actual meteorological data, in particular the precipitation, at the two measuring stations and the measured meteorological data would be reduced.

\section{Results}

\subsection{Magnetic measurements}

In Figure 5, the hysteresis parameter $H_{c}$ is plotted as a function of time for all three data sets. Mean hysteresis parameters for the overlapping period of the three data sets are summarised in Table 5. The mean values were calculated assuming lognormal distributions. Hysteresis curves are depicted for two samples which display $H_{c}$ values near the limits of those measured (Figure 5). The hysteresis curves generally saturated in a field as low as $230 \mathrm{mT}$, which is typical for iron and magnetite, but is too low for hematite or goethite as the main carrier of the magnetic signal.

Between the two $\mathrm{PM}_{70}$ data sets there are large variances between the total magnetic content $\left(m_{s}\right)$ and concentration-dependent terms $\left(M_{s}\right)$, but not between the grain size dependent term $H_{c}$ (Table 5). Comparing the $\mathrm{PM}_{70}$ samples from Pasing and Westend (Table 5), it can be seen that the total magnetic content $\left(m_{s}\right)$ at Pasing is more than twice the total level at Westend, and $M_{s}$ is also significantly higher at Pasing than at Westend. At Pasing, the mass dependent term $m_{s}$ is larger for the $\mathrm{PM}_{70}$ filter samples than the $\mathrm{PM}_{10}$ samples, however, the concentration dependent term $M_{s}$ is similar, indicating that the concentration of magnetic minerals in the range $10<d<70 \mu \mathrm{m}$ is similar to that for $d<10 \mu \mathrm{m}$ (Table 5). The values of $H_{c}$ are similar to those measured by Matzka (1997) for two other locations in Munich, and the $m_{s}$ and $M_{s}$ values he obtained are closer to those from Westend than Pasing. 
The thermomagnetic curve (Figure 5) of the Westend $\mathrm{PM}_{70}$ sample for the week 25/3/99-01/4/99 displays a Curie temperature of $\approx 580{ }^{\circ} \mathrm{C}$ which is a clear indicator of the presence of magnetite, the iron oxide $\mathrm{Fe}_{3} \mathrm{O}_{4}$. Assuming from the thermomagnetic data and hysteresis data, that the dominant magnetic mineral is magnetite, then it is possible to estimate the mean grain size from the magnetic parameter $H_{c}$ for all the samples to be in the range 0.2-5 $\mu \mathrm{m}$ (Dunlop \& Özdemir, 1997). As magnetite has a saturation magnetisation of $92 \mathrm{Am}^{2} \mathrm{~kg}^{-1}$ (Dunlop \& Özdemir, 1997), then if magnetite is the primary magnetic carrier, then the mean content of magnetite can be calculated to be in the order of $0.3-0.6 \%$ by mass (Table 5 ).

\subsection{SEM observations}

SEM observations were made on a few randomly selected samples. It was found that the atmospheric PM most likely to contribute to the magnetic signal, i.e., ironbearing particles, were iron oxide grains of generally less than $5 \mu \mathrm{m}$ in diameter. There were only a few iron oxide grains larger than this in the $\mathrm{PM}_{70}$ samples. The SEM had EDX facilities sensitive to oxygen, however, it was not possible to quantify the valence state of the iron oxide grains. Qualitatively there did not appear to be a wide range iron oxide valency states, except a few particularly iron-rich iron oxides. Considering the results from Mössbauer studies of Munich PM (Muxworthy et al., 2000), it is suggested that these iron-rich iron oxides were near-stoichiometric iron grains coated with surface oxidation products. The SEM observations support the magnetic results in that the magnetic particles in the samples were mostly iron oxide, with grain size less than $5 \mu \mathrm{m}$.

\subsection{Principal Component Analysis}

The magnetic results were compared to the pollution and meteorological data using PCA. This method of factor analysis was preferred over more elaborate techniques, as this technique has been used in similar studies (e.g., Morris et al., 1995; Shu et al., 2000). In the principal component analysis, the magnetic mass and concentration dependent data and the mass data were transformed using logarithmic function 
(base 10), following the procedure of Morris et al. (1995). This transformation accommodates the log-normal distributions of these parameters (Dunlop \& Özdemir, 1997; Kim et al., 2001). However, purely for reference, it was found that the PCA results for untransformed and transformed data were almost identical.

The meteorological data (precipitation, sun hours, wind speed, air pressure and relative humidity) was not measured at the same locations as the pollution data, however, it was taken as global, that is, there would be expected to be little spatial variation within Munich in the variance when averaged weekly. The pollution data was thought to be more localised, however, only the $\mathrm{CO}, \mathrm{NO}, \mathrm{NO}_{2}$ and $\mathrm{SO}_{2}$ pollution data was collected at each site, with the other pollution variables, i.e., ozone, benzene, touline and o-dimethylbenzene, only being measured at Lothstrasse. Initially the variance between all the pollution data from L8.3 was correlated, for which there was found to be a very strong correlation (Spearman's $\rho<0.01$ for all correlations except o-dimethylbenzene with ozone, where $\rho$ was only significant at the 0.05 level). The first factor accounted for $78 \%$ of the variance. The second factor contributed $10 \%$ of the variance, and was seen to be controlled by o-dimethylbenzene. This suggests that the behaviour of the pollutants $\mathrm{CO}, \mathrm{NO}, \mathrm{NO}_{2}$ and $\mathrm{SO}_{2}$ were representative of all the pollutants. In fact, to reduce the matrix during PCA and for simplicity, only the pollution data for $\mathrm{NO}_{2}$ was considered.

The PCA factor plot of the pollution, meteorological and hysteresis data for the $\mathrm{PM}_{70}$ filter from Westend, is shown in component space for the first two components in Figure 5a. The first two factors contribute $62 \%$ of the variance, while the third component contributes only $14 \%$. There is a strong correlation between $H_{c}$ and the number of sun hours, but $H_{c}$ shows no or little dependence on $\mathrm{NO}_{2}$. The concentration dependent magnetic property $M_{s}$ is nearly independent of the pollutants. There is a significant correlation between PM mass and the magnetic moment $(\rho<0.01)$. Increases in wind speed and precipitation are seen to decrease the total magnetic moment, as well as $\mathrm{NO}_{2}$, suggesting that the pollution source is local.

In Figure 5b, the pollution, meteorological and magnetic hysteresis data for the $\mathrm{PM}_{70}$ filter from Pasing, are plotted in component space for the first two factors representing $63 \%$ of the variance. The third factor only contributes to $13 \%$ of the 
variance. On the factor 1 axis, there is a strong correlation between $H_{c}$ and the number of sun hours $(\rho<0.01)$, and a strong negative correlation between both $H_{c}$ and the relative humidity, for which $\rho<0.01$. Factor 2 consists of a strong correlation between air pressure and the particulate mass and a strong negative correlation with the wind speed, precipitation and the concentration dependentmagnetisation $\left(M_{s}\right)$. Surprisingly there is no significant correlation between the mass and mass-dependent magnetic moment $m_{s}(\rho>0.05)$.

In Figure 5c, the factor plot of the pollution, meteorological data and $\mathrm{PM}_{10}$ magnetic hysteresis data is depicted for the first two factors $(63 \%$ of the variance - the third factor only contributes to $14 \%$ of the variance). The factor plot is similar to that for the $\mathrm{PM}_{70}$ filter samples from the same location (Figure 5b), except $\mathrm{PM}_{10}$ mass displays less correlation $(\rho>0.05)$ with air pressure than the $\mathrm{PM}_{70}$ mass $(\rho<0.01)$.

\section{Discussion}

\subsection{Characterisation of primary magnetic carrier}

The dominant magnetic mineral is magnetite, which is suggested from both the intensity of the saturating field during hysteresis, and the thermomagnetic analysis which was conducted on a selection of samples. This is in agreement with other similar studies, which also identified magnetite as the primary magnetic mineral in urban particulate matter (e.g., Dedik et al., 1992; Matzka, 1997; Matzka \& Maher, 1999).

That hematite was not detected is unusual as it has been identified in numerous Mössbauer studies (e.g., Kopcewicz \& Kopcewicz, 1992; Hoffmann et al., 1996). However, hematite was not detected in the detailed Mössbauer study of Munich particulate matter by Muxworthy et al. (2000). This discrepancy maybe due to the oxidation of magnetite particulate matter either in air or during storage before measurement in the previous studies, and/or in the grain size range examined. For example, both Kopcewicz \& Kopcewicz (1992) and Hoffmann et al. (1996) found nearly all of their hematite in the most easily oxidiseable grain-size range, i.e., 
the room-temperature, superparamagnetic grain-size range $(\approx 25-30 \mathrm{~nm}$ (Banerjee, 1971)). In the present study, the superparamagnetic fraction was not examined.

Combining the magnetic parameters with the evidence from the SEM analysis, then it appears that most of the magnetic atmospheric PM is in the range 0.2$5 \mu \mathrm{m}$. This is in agreement with other air PM studies of iron and iron oxides (e.g., Hoffmann et al., 1996; Matzka, 1997; Matzka \& Maher, 1999; Rizzio et al., 1999), and in particular in agreement with the study of Fruhsorfer \& Niessner (1994) who undertook particle-size analysis of airborne PM collected in Munich in April 1993. For reference it should be noted, grains $<4.6 \mu \mathrm{m}$ are especially dangerous to humans as they can be inhaled into the bronchial region, and even more dangerous to humans are grains $<1.1 \mu \mathrm{m}$ which can be deposited in the alveolar region (Rizzio et al., 1999).

\subsection{Comparison of magnetic parameters with pollution and meteorological data}

There is generally strong correlations between the coercive force and the meteorological data such as sun hours and relative humidity, indicating that the PM grain size is controlled by atmospheric processes rather than source changes. This is reflected in the behaviour of $H_{c}$ in Figure 5, where it is seen that the form of the three curves are similar, but the amplitudes of the highs and lows are different, indicating that the two stations are experiencing common events. The coercive force is seen to increase with the number of sunlight hours, but decrease with the relative humidity, reflecting the intrinsic relationship between sun hours and relative humidity. The decrease in $H_{c}$ with the relative humidity, indicates that preferentially the particles which are responsible for the highest coercivities are removed, i.e., the particles at the lower limit of the grain-size range. The effect of relative humidity can be explained by considering the hygroscopic nature of iron oxides (Hoffmann et al., 1996). Iron oxides like magnetite, have relatively small band-gaps and can become photo-excited (Toledano et al., 1998), making them able to chemisorb $\mathrm{SO}_{2}$, which converts to sulfate at the gas-solid interface. This interaction layer increases the hygroscopic behaviour of otherwise unwettable particles (Kopcewicz \& Kopcewicz, 1992). This results in particle growth and a corresponding decrease in residency 
time. The smaller particles will be the most strongly affected as they have the highest relative growth.

The effect of precipitation, which is usually thought to remove air particulate matter, is not clear. At Westend there is a strong inverse correlation between both PM mass and the magnetic moment, and the precipitation levels as expected $(\rho<0.01)$. However, at Pasing for $\mathrm{PM}_{10}$ mass and the magnetic moment the correlation with the precipitation levels is weaker $(\rho<0.05)$, and whilst Pasing $\mathrm{PM}_{70}$ mass displays a strong correlation with precipitation levels $(\rho<0.01)$, the magnetic moments values displays no significant correlation $(\rho>0.05)$. The behaviour at Pasing can be explained if there is a large percentage of non-magnetic material in the $\mathrm{PM}_{70}$ grain size which is removed by precipitation, indicating that the grain-size distribution of the magnetic and total particulate matter are not alike. The differences between $\mathrm{PM}_{70}$ data sets from Pasing and Westend reflect differences in the PM source.

On comparison of the magnetic data with the pollution data, there are clear differences between the two localities Pasing and Westend. The mass-dependent magnetic moment $m_{s}$ for the Westend $\mathrm{PM}_{70}$ sequence, displays a strong correlation with both the mass and $\mathrm{NO}_{2}$, however at Pasing none of the magnetic parameters display significant correlations with the pollution or mass data for neither the $\mathrm{PM}_{70}$ nor $\mathrm{PM}_{10}$ sequences, which means that susceptibility cannot be used as a standard indicator of the total PM mass as suggested by Morris et al. (1995). It is suggested that the main source of the magnetic PM at Westend is the same as the pollution data $\mathrm{NO}_{2}$, i.e., combustion processes, but this is not the case at Pasing. The pollution at Westend is thought to be solely derived from vehicles, whereas Pasing is situated near a major railway yard which is expected to contribute magnetic PM which is not associated with gaseous pollution data, e.g., abrasion/corrosion magnetic PM (Olson \& Skogerboe, 1975). This theory is supported by comparing the average pollution levels with the $\mathrm{PM}_{70} m_{s}$ at Pasing and Westendstrasse. The magnetic moment $m_{s}$ at Westend is nearly half the value at Pasing, i.e., (Westend $\left.m_{s}\right) /\left(\operatorname{Pasing} m_{s}\right)=$ $61 \%$, but the corresponding percentages calculated from the data for $\mathrm{NO}_{2}(78 \%)$, $\mathrm{SO}_{2}(87 \%)$ and PM mass concentration $(75 \%)$ are much greater. Only CO $(60 \%)$ displays a similar percentage, and NO displays a much smaller percentage, i.e., $44 \%$. It appears therefore that at location Westend the magnetic and pollution data have the same source, but at Pasing there is another contribution to the mag- 
netic signal. By comparing the $\mathrm{PM}_{10}$ and $\mathrm{PM}_{70}$ magnetic moments and the mass concentration values from Pasing, it appears that there is a significant contribution from the larger grain sizes, i.e., $10<d<70 \mu \mathrm{m}$. Though this is reflected by only a small decrease in the mean $H_{c}$ from $6.3 \mathrm{mT}$ to $5.9 \mathrm{mT}$ (Table 5) suggesting that most of the "extra" magnetic loading in the $\mathrm{PM}_{70}$ sample is in a grain size not significantly greater than $10 \mu \mathrm{m}$.

The total mass dependent terms, are highest during the winter, when there is a corresponding high in the other pollution data. This is especially prevalent during calm, dry days with high air pressure during the winter, i.e., during an inversion. During these periods the biggest divergences between PM mass and magnetic massdependent term $m_{s}$ are observed, indicating a secondary non-magnetic PM source.

Variations in wind speed have only a minor effect on the grain size and concentration of the magnetic atmospheric PM (Figure 5). Assuming that PM collected during higher wind speeds, reflects a larger sampling distance, then the constant loading level of magnetic PM, combined with a constant grain size indicates a common source. However, as stated previously the wind speed data should be treated with caution as it is believed that is subject to channelling effects, which is known to effect measured wind speeds (Kastner-Klein \& Plate, 1999).

\section{Conclusions}

Principal component analysis of particulate matter collected in Munich in 19981999, has found that generally the magnetic hysteresis parameters have a stronger correlation with the meteorological data than with the pollution data. Correlation between saturation moment and pollution level was found to be highly location dependent, with the best correlation found for the site where the pollution is thought to be mainly vehicular derived. The grain size parameter $H_{c}$ displays a strong correlation with the meteorological data, in particular the number of sun hours and the relative humidity, which has not been previously reported.

These results are of significance for the interpretation of magnetic susceptibility data of particulate matter, which is the magnetic parameter most commonly used for 
magnetic studies on particulate matter (e.g., Morris et al., 1995; Shu et al., 2000). As the magnetic susceptibility is related to both the magnetic moment and the coercive force $\left(H_{c}\right)$ of the sample, then this gives rise to two important notes of caution. Firstly, that at one location there was a strong correlation between the magnetic moment $m_{s}$ and the pollution data, but not at the other, directly demonstrates that the magnetic susceptibility is not always correlated with the total particulate mass, implying that measuring susceptibility as a fast method of monitoring the bulk PM can be inaccurate. Secondly, that the grain size related parameters are strongly related to the meteorological data, implies that measuring susceptibility as a fast method of assessing the bulk magnetic content can be misleading, as susceptibility is inversely related to $H_{c}$.

The primary magnetic mineral was found to be magnetite. The dominant grain size is $0.2-5 \mu \mathrm{m}$, though there is evidence for some grains being slightly greater than $10 \mu \mathrm{m}$. This is important to health related studies, as grains $<4.6 \mu \mathrm{m}$ can be inhaled into the bronchial region (Rizzio et al., 1999). The concentration of magnetite was in the range $0.3-0.6 \%$ by mass.

\section{Acknowledgements}

We thank Dr. P. Köpke of the Meteorologisches Institut, Universität München, for his advice and comments. The filter samples and the pollution data were kindly provided by Mr. Weber of the Bayerisches Landesamt für Umweltschutz. The meteorological data was provided by Dr. P. James of the Technische Universität München. The authors also benefited from fruitful discussions with Dr. Michael Winklhofer and Roman Leonhardt. ARM was funded by the European Union (contract no. ERBFMRXCT98-0247), as part of the European Network for Mineral Magnetic Studies of Environmental Problems (MAG-NET).

\section{References}

Banerjee, S. K. 1971. New grain size limits for palaeomagnetic stability in hematite. Nature Phys. Sci., 232, 15-16. 
Bayerisches Landesamt für Umweltschultz. 1998. Lufthygienischer Jahresbericht 1997. München: Bayerisches Landesamt für Umweltschultz.

Charlesworth, S. M., \& Lees, J. A. 1997. The use of mineral magnetic measurements in polluted urban lakes and deposited dusts, Coventry, UK. Phys. Chem. Earth, 22(1-2), 203-206.

Dedik, A. N., Hoffmann, P., \& Ensling, J. 1992. Chemical characterization of iron in atmospheric aerosols. Atmospheric Environment, 26A(14), 2545-2548.

Dunlop, D. J., \& Özdemir, Ö. 1997. Rock Magnetism: Fundamentals and Frontiers. Cambridge University Press.

Fruhsorfer, P., \& Niessner, R. 1994. Identification and classification of airborne soot particles using an automated SEM/EDX. Mikrochim. Acta, 113, 239-250.

Hoffmann, P., Dedik, A. N., Ensling, J., Weinbruch, S., Weber, S., Sinner, T., Gutlich, P., \& Ortner, H. M. 1996. Speciation of iron in atmospheric aerosol samples. J. Aerosol Sci., 27, 325-337.

Kapička, A., Jordanova, N., Petrovský, E., \& Ustjak, S. 2000. Magnetic stability of power-plant fly ash in different soil solutions. Phys. Chem. Earth., 25(5), 431-436.

Kastner-Klein, P., \& Plate, E. J. 1999. Wind-tunnel study of concentration fields in street canyons. Atmos. Environ., 33, 3973-3979.

Kim, W-K., Kim, S. H., Lee, D. W., Lee, S., Lim, C. S., \& Ryu, J. H. 2001. Size analysis of automobile soot particles using field-flow fractionation. Envrion. Sci. Tech., in press.

Kopcewicz, B., \& Kopcewicz, M. 1992. Seasonal variations of iron concentration in atmospheric aerosols. Hyperfine Interactions, 71, 1457-1460.

Matzka, J. 1997. Magetische, elektronenmikroskopische und lichtmikroskopische Untersuchungen an Stäuben und Aschen sowie an einzelnen Aschepartikeln. M.Phil. thesis, Universität München.

Matzka, J., \& Maher, B. A. 1999. Magnetic biomonitoring of roadside tree leaves: identification of spatial and temporal variations in vehicle- derived particulates. Atmospheric Environment, 33, 4565-4569.

Morris, W. A., Versteeg, J. K., Bryant, D. W., Legzdins, A. E., McCarry, B. E., \& Marvin, C. H. 1995. Preliminary comparisons between mutagenicity and magnetic- susceptibility of respirable airborne particulate. Atmospheric Environment, 29, 3441-3450. 
Muxworthy, A. R., Petersen, N., Schmidbauer, E., \& Matzka, J. 2000. Magnetic characterisation of urban dust and potential use of magnetic monitoring as a method of health risk assessment (abstract). Geophys. Res. Abst., 2(25th EGS Gen. Ass.), SE29.02.

Olson, K. W., \& Skogerboe, R. K. 1975. Identification of soil lead compounds from automotive sources. Environ. Sci. \& Tech., 9, 227-230.

Rizzio, E., Giaveri, G., Arginelli, D., Gini, L., Profumo, A., \& Gallorini, M. 1999. Trace elements total content and particle sizes ditribution in the air particulate matter of a rural-residential area in the north Ialy investigated by instrumental neutron activation anaylsis. Sci. Tot. Environ., 226, 47-56.

Shu, J., Dearing, J. A., Morse, A. P., Yu, L., \& Li, C. 2000. Magnetic properties of daily sampled total suspended particulates in Shanghai. Environ. Sci. \& Tech., 34, 2393-2400.

Thompson, R., \& Oldfield, F. 1986. Environmental Magnetism. London: Allen and Unwin Publishers.

Toledano, D. S., Dufresne, E. R., \& Henrich, V. E. 1998. Photoexcited $\mathrm{Fe}_{2} \mathrm{O}_{3}$ surfaces: Properties and chemisorption. J. Vac. Sci. Technol. A, 16, 1050-1054.

Weber, S., Hoffman, P., Ensling, J., Dedik, A. N., Weinbruch, S., Miehe, G., Gütlich, P., \& Ortner, H. M. 2000. Characterization of iron compounds from urban and rural aerosol sources. J. Aerosol. Sci., 31(8), 987-997.

Xie, S. J., Dearing, J. A., Bloemendal, J., \& Boyle, J. F. 2000. The organic matter content of street dust in Liverpool, UK, and its associateion with dust magnetic properties. Atmos. Environ., 34, 269-275. 
Table 1

Summary of the mean hysteresis parameters, the mass and percentage by mass (assuming magnetite) of magnetic material for the three data sets examined in this study, for the 17 week overlap period $(27 / 1 / 99-$ $27 / 5 / 99)$. The weekly means are tabulated, and were calculated assuming lognormal distributions.

\begin{tabular}{|c|c|c|c|c|c|c|}
\hline \multirow{2}{*}{$\begin{array}{l}\text { Hysteresis } \\
\text { parameter }\end{array}$} & \multicolumn{2}{|c|}{ Pasing $\mathrm{PM}_{10}$} & \multicolumn{2}{|c|}{ Pasing $\mathrm{PM}_{70}$} & \multicolumn{2}{|c|}{ Westend $\mathrm{PM}_{70}$} \\
\hline & mean & $\sigma$ & mean & $\sigma$ & mean & $\sigma$ \\
\hline$H_{c}\left(\times \mu_{0} \mathrm{mT}\right)$ & 6.3 & 0.4 & 5.9 & 0.2 & 5.9 & 0.2 \\
\hline$m_{s}\left(\times 10^{-7} \mathrm{Am}^{2}\right)$ & 23 & 3 & 40 & 2 & 18 & 2 \\
\hline$M_{s}\left(\mathrm{mAm}^{2} / \mathrm{kg}\right)$ & 510 & 70 & 490 & 30 & 300 & 20 \\
\hline mass (mg) & 4.5 & 0.8 & 8.1 & 1.2 & 6.1 & 1.1 \\
\hline$\%$ by mass & 0.56 & 0.07 & 0.53 & 0.03 & 0.32 & 0.02 \\
\hline
\end{tabular}

Where $\sigma$ is the standard deviation. 


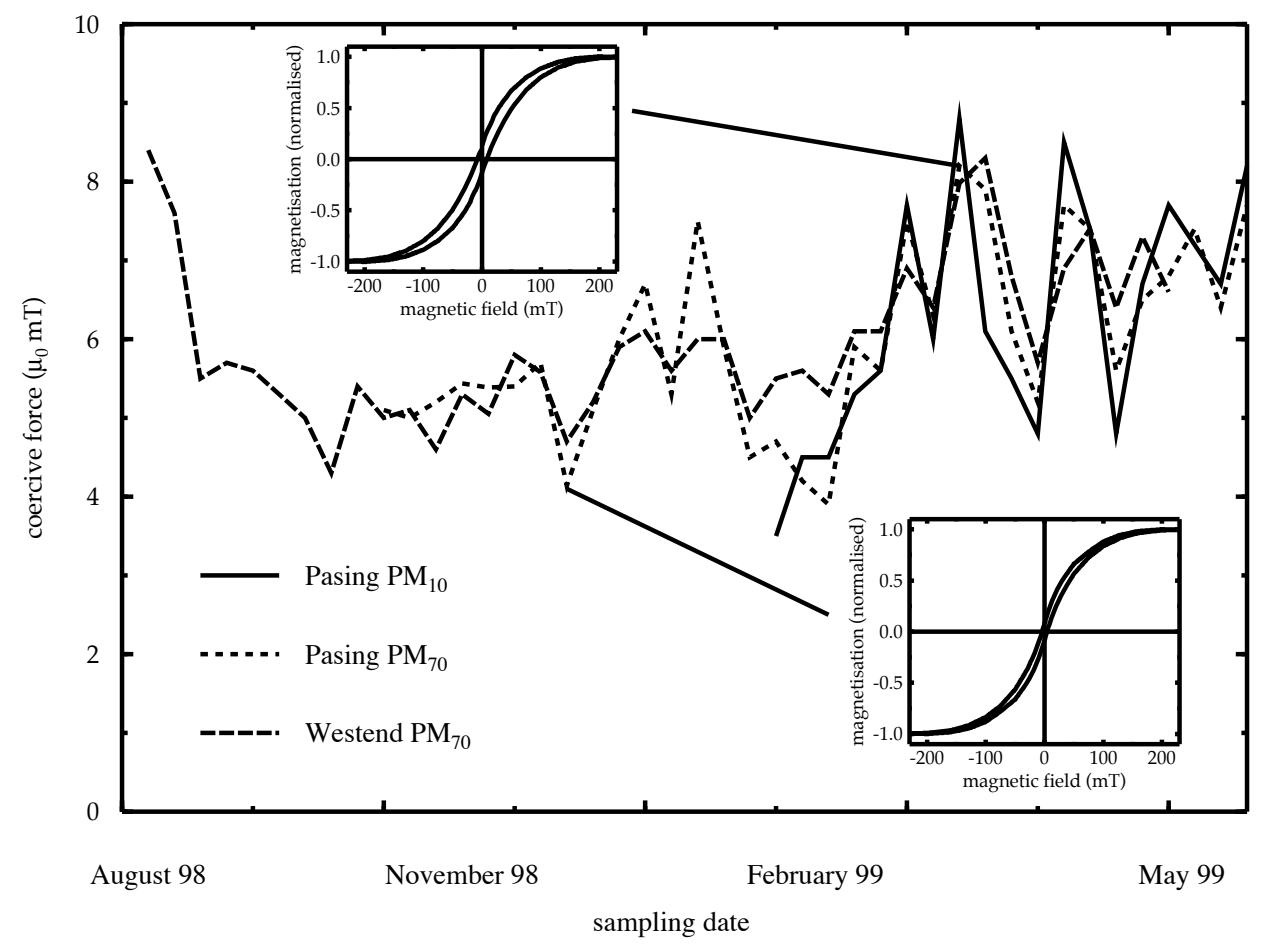

Fig. 1. $H_{c}$ as a function of time for the three data sets considered in this study. Westend $\mathrm{PM}_{70}$ has the longest sequence, though it stops three weeks before the two data sets from Pasing. Two hysteresis curves for two $\mathrm{PM}_{70}$ samples from Pasing; for the lower curve $H_{c}=4.1 \mathrm{mT}$ and for the upper $H_{c}=8.2 \mathrm{mT}$. The average hysteresis parameters are summarised in Table 5 . 


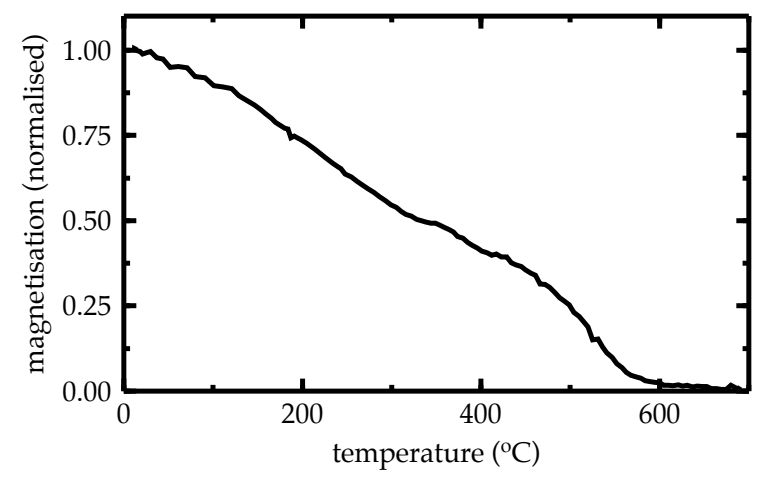

Fig. 2. Thermomagnetic curve for a $\mathrm{PM}_{70}$ sample from Westend for the week $25 / 3 / 99-01 / 4 / 99$. The warming curve Curie temperature is that of magnetite $\left(\mathrm{T}_{c}\right.$ $=580{ }^{\circ} \mathrm{C}$ ). Heating was in air. 

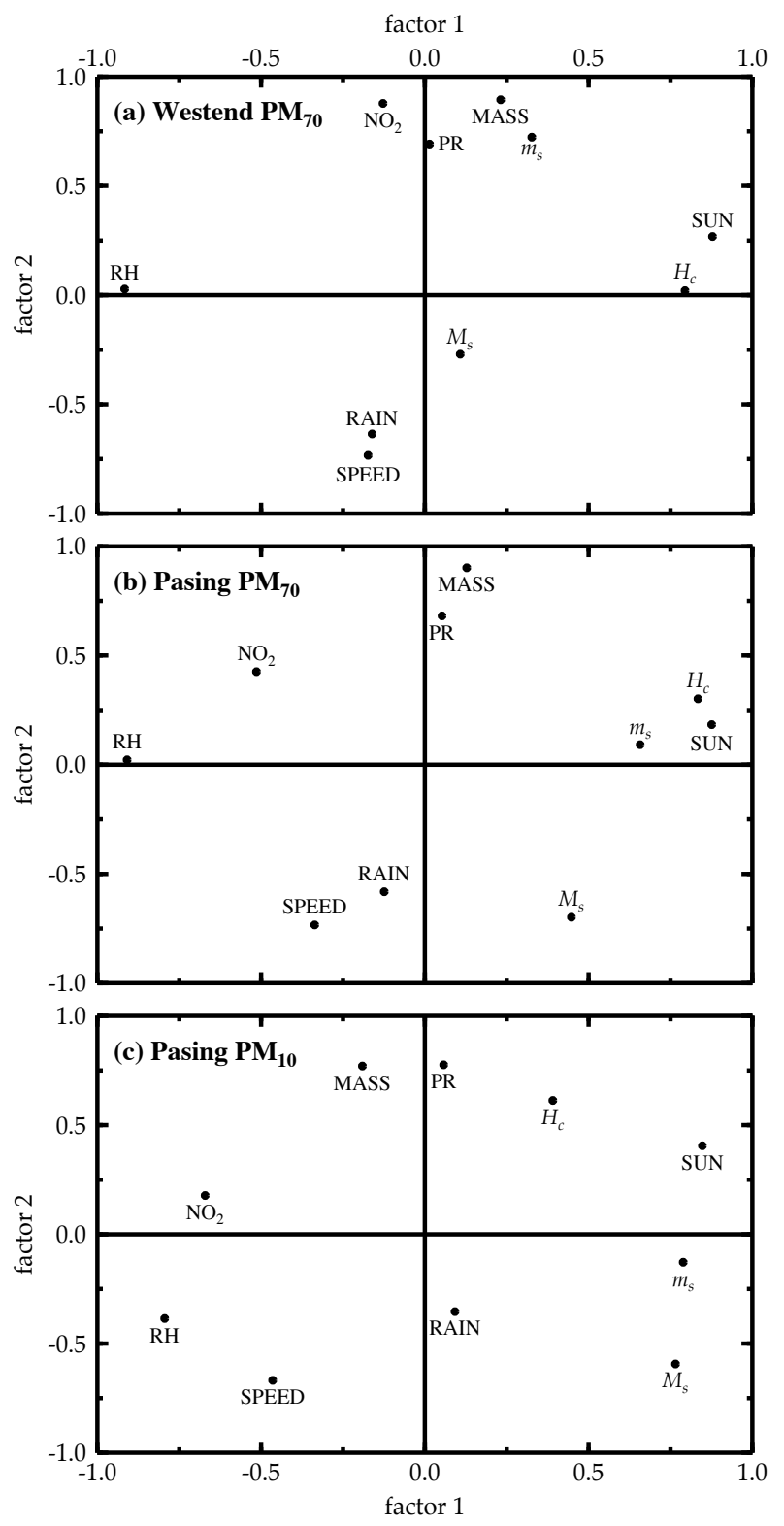

Fig. 3. Factor loading plots derived from PCA for the magnetic data $\left(H_{c}=\right.$ coercive force, $m_{s}=\log _{10} m_{s}$ and $M_{s}=\log _{10} M_{s}$ ) sequences from a) Westend $\mathrm{PM}_{70}$, b) Pasing $\mathrm{PM}_{70}$ and c) Pasing $\mathrm{PM}_{10}$, with representative pollution and meteorological data. MASS is the $\log _{10}$ of the mass of the samples, SUN is the number of sun hours, RAIN is the precipitation, SPEED is the wind speed, PR is the air pressure, RH is the relative humidity and the pollutant $\mathrm{NO}_{2}$. 